\title{
Characterization of the interaction between P3ATs with PCBM on ITO using in situ Raman spectroscopy and electrochemical impedance spectroscopy
}

\author{
Danielly Cristina Bento ${ }^{1} \cdot$ Edilene Assunção da Silva $^{2}$ - Clarissa de Almeida Olivati ${ }^{2}$ \\ Guy Louarn ${ }^{3} \cdot$ Henrique de Santana ${ }^{1}$
}

Received: 7 April 2015/Accepted: 29 June 2015/Published online: 8 July 2015

(C) Springer Science+Business Media New York 2015

\begin{abstract}
In this study, phenyl- $\mathrm{C}_{61}$-butyric acid methyl ester (PCBM) was deposited onto indium tin oxide (ITO) using the Langmuir-Schaefer technique, and poly(3methylthiophene) (P3MT) and poly(3-hexylthiophene) (P3HT) were then electrochemically synthesized onto the ITO/PCBM, producing PCBM/P3MT and PCBM/P3HT films respectively. These films are widely used to create heterojunctions in organic photovoltaic cells, and they were produced in this study in order to monitor the charge transfer process between the P3ATs and PCBM. Cyclic voltammetry (CV) of the ITO/PCBM/P3AT systems demonstrates dislocation of oxidation and reduction peaks and a variation in the current of these peaks in relation to those observed in ITO/P3ATs. Charge transfer resistance $\left(\mathrm{R}_{\mathrm{CT}}\right)$ were determined using electrochemical impedance spectroscopy (EIS) to produce Nyquist plots at open circuit potential and at different applied potentials. ITO/PCBM/ P3HT had a lower $\mathrm{R}_{\mathrm{CT}}$ value than ITO/P3HT and ITO/ PCBM/P3MT. Bode phase plots produced using EIS indicated that the charge transfer process in ITO/PCBM/P3HT is associated with polaron conduction (radical cation) and in ITO/PCBM/P3MT with bipolar conduction (dication). This study of the behaviour observed in these systems using CV and EIS techniques was supplemented with ex situ and in situ Raman spectroscopy. Structural variations
\end{abstract}

Henrique de Santana

hensan@uel.br

1 Departamento de Química, CCE, Universidade Estadual de Londrina, Londrina, PR 86051-990, Brazil

2 Faculdade de Ciência e Tecnologia (FCT), UNESP, Presidente Prudente, SP 19060-900, Brazil

3 Institut des Matériaux Jean Rouxel, Université de NantesCNRS, 44322 Nantes, France were observed in segments of the P3HT polymer chain when interacting with $\mathrm{PCBM}$ in the ITO/PCBM/P3HT system, but not for ITO/P3MT in the ITO/PCBM/P3MT system. The charge transfer observed between PCBM and P3HT was associated with the stabilization of the radical cation species found in $\mathrm{P} 3 \mathrm{HT}$ in this material.

\section{Introduction}

Organic photovoltaic cells (OPVs) used to generate energy through the absorption of sunlight have been the subject of intense study as a result of the high demand for renewable, clean and affordable energy sources [1-4]. OPVs are made up of an active layer consisting of organic semiconductor materials, such as electron-donating conjugated polymers, and another species with a high electron affinity, such as electron receptor fullerene $\left(\mathrm{C}_{60}\right)$ derivates $[1,2,4-8]$. Studies into active layers made up of poly(3-alkylthiophenes) (P3ATs) and fullerenes have demonstrated that photoinduced charge transfer in $\mathrm{P} 3 \mathrm{ATs} / \mathrm{C}_{60}$ compounds results in the formation of positive polarons on P3ATs and negative polarons on $\mathrm{C}_{60}$, increasing the separation of charge in the active layer and subsequently improving the efficiency of OPVs $[9,10]$.

For this reason, these extremely photosensitive poly(3alkylthiophenes) (P3ATs) are frequently used as optical absorbers in heterojunctions, as they absorb a sufficient amount of light in the visible region [1, 5, 11-15]. In addition, P3ATs are p-type semiconductors [16-18] and have positively charged structures along their chains, these being the radical cations (polarons) and dications (bipolaron) responsible for the transfer of positive charge. Phenyl- $\mathrm{C}_{61}$-butyric acid methyl ester (PCBM) can be used as an n-type conductor, as it has the capacity to generate 
negative polarons and bipolarons, the radical anions and dianions responsible for electron transfer [1, 2, 4-10, 19-22].

In this study, films were generated from PCBM and two P3ATs-poly(3-methylthiophene) and poly(3-hexylthiophene) —on an indium tin oxide (ITO) electrode in order to study electrochemical properties and charge transfer between the P3ATs and PCBM. The system made up of ITO/PCBM and poly(3-methylthiophene) (P3MT) was named ITO/PCBM/P3MT and the system made up of ITO/ PCBM and poly(3-hexylthiophene) (P3HT) was named ITO/PCBM/P3HT.

The electrochemical behaviour of the two ITO/PCBM/ P3AT systems was verified using cyclic voltammetry $(\mathrm{CV})$ and charge transfer resistance processes were studied using electrochemical impedance spectroscopy (EIS), at open circuit potential (OCP) and a range of applied potentials. The results observed on Nyquist and Bode phase plots were supplemented using ex situ and in situ spectra in order to study the predominance of aromatic, radical cation and dication segments in P3ATs, which could be favoured through the interaction with PCBM.

\section{Experiment}

\subsection{Reagents}

The monomers 3-methylthiophene $\left(\mathrm{C}_{5} \mathrm{H}_{7} \mathrm{~S}\right) 98.0 \%$ and 3-hexylthiophene $\left(\mathrm{C}_{10} \mathrm{H}_{16} \mathrm{~S}\right) 99.0 \%$, as well as phenyl$\mathrm{C}_{61}$-butyric acid methyl ester (PCBM) $99.5 \%$, were purchased from Aldrich were used as received. Lithium perchlorate $\left(\mathrm{LiClO}_{4}\right)$ with a purity of $99.0 \%$ purchased from Acros Organics was used as the supporting electrolyte. HPLC grade acetonitrile $\left(\mathrm{CH}_{3} \mathrm{CN}\right)$ with a purity of $99.5 \%$ was purchased from JT Baker and chloroform P.A was purchased from Biotec.

\subsection{Electrochemical synthesis and cyclic voltammetry}

A $0.30 \mathrm{mg} \mathrm{mL}^{-1}$ solution of PCBM in chloroform was deposited on ITO using the Langmuir-Schaefer technique, producing ITO/PCBM. The P3ATs were electrochemically synthesised onto ITO/PCBM using the chronoamperometry (CA) technique with a $0.50 \mathrm{~cm}^{2}$ platinum plate counter electrode, producing an ITO/PCBM/P3ATs system with an average area of $0.30 \mathrm{~cm}^{2}$. Potentials were determined using $\mathrm{Ag} / \mathrm{AgCl}$ deposited in a Luggin capillary containing a $0.100 \mathrm{~mol} \mathrm{~L}{ }^{-1}$ solution of $\mathrm{LiClO}_{4}$ in acetonitrile $\left(\mathrm{LiClO}_{4} /\right.$ $\mathrm{ACN})$ as the reference electrode.

The P3MT and P3HT poly(3-alkylthiophenes) were electrochemically synthesised onto ITO/PCBM using the conditions described in Table 1.
$\mathrm{CA}$ and $\mathrm{CV}$ curves were obtained for a rate of $50 \mathrm{mV} \mathrm{s}^{-1}$ using an Autolab PGSTAT 302N potentiostat/galvanostat coupled with a microcomputer with NOVA 1.8 software.

\subsection{Electrochemical impedance spectroscopy (EIS)}

Impedance plots obtained at open circuit potential (OCP) and a range of applied potentials were obtained using an Autolab PGSTAT $302 \mathrm{~N}$ potentiostat with a FRA32M impedance module, varying the frequency from $100 \mathrm{kHz}$ to $0.01 \mathrm{~Hz} . \mathrm{Ag} / \mathrm{AgCl}$ deposited in a Luggin capillary containing $0.100 \mathrm{~mol} \mathrm{~L}^{-1} \mathrm{LiClO}_{4} / \mathrm{ACN}$ solution was used as the reference electrode. OCP values were determined using a disturbance potential of $\pm 10 \mathrm{mV}$. EIS measurements were taken by applying fixed potentials after a pause of $5 \mathrm{~min}$ in order to allow a constant current to be reached.

Table 2 presents OCP values, potential values similar to the oxidation potentials obtained using cyclic voltammetry, presented in Fig. 1, and used for EIS at different potentials, and maximum frequencies $(f)$ of semicircles in Nyquist plots produced for each system.

\subsection{Raman spectroscopy}

Ex situ and in situ Raman spectra were obtained using a portable DeltaNu Advantage532 ${ }^{\circledR}$ Raman spectrometer, excited at $532 \mathrm{~nm}$ with a resolution of $8 \mathrm{~cm}^{-1}$. DeltaNu NuSpec software was used with baseline resources to remove background fluorescence. As well as in situ Raman spectra, potentials similar to those observed for oxidation and reduction during cyclic voltammetry were applied, presented in Fig. 1, using a Microquímica MQPG-01 potentiostat coupled with a microcomputer. Potentials were applied using $\mathrm{Ag} / \mathrm{AgCl}$ deposited into a Luggin capillary containing $0.100 \mathrm{~mol} \mathrm{~L}^{-1} \mathrm{LiClO}_{4} / \mathrm{ACN}$ solution and at a rate of $50 \mathrm{mV} \mathrm{s}^{-1}$.

\section{Results}

Cyclic voltammetries obtained for a potential scan between -1.50 and $2.50 \mathrm{~V}$ for ITO/P3MT and ITO/P3HT during a previous study [23], and for the ITO/PCBM/P3ATs in a $0.100 \mathrm{~mol} \mathrm{~L}^{-1}$ solution of $\mathrm{LiClO}_{4} / \mathrm{ACN}$, are presented in Fig. 1.

Cyclic voltammetry for ITO/PCBM/P3MT, presented in Fig. 1a, when compared to cyclic voltammetry for ITO/ P3MT, demonstrated a slight reduction in current intensity for the oxidation peaks and a displacement of the second oxidation peak from +1.80 to $+2.30 \mathrm{~V}$. The reduction peak for ITO/PCBM/P3MT demonstrated an increase in current and a negative displacement from +0.30 to $-0.47 \mathrm{~V}$ compared to the results obtained for ITO/P3MT. 
Table 1 Experimental conditions for the synthesis of P3AT films on ITO/PCBM using chronoamperometry $(\mathrm{CA})$

\begin{tabular}{lllll}
\hline Films & Concentration $\left(\mathrm{mol} \mathrm{L}^{-1}\right)$ & Time $(\mathrm{s})$ & $\mathrm{E}(\mathrm{V}$ vs. $\mathrm{Ag} / \mathrm{AgCl})$ & $\mathrm{J}\left(\mathrm{mA} \mathrm{cm}^{-2}\right)$ \\
\hline P3MT & 0.035 & 180 & 1.65 & 3.97 \\
P3HT & 0.040 & 180 & 1.75 & 3.90 \\
\hline
\end{tabular}

Table 2 Open circuit potential (OCP) values for different potentials and maximum frequencies $(f)$ for PCBM/P3AT films

\begin{tabular}{|c|c|c|c|c|c|}
\hline \multirow[t]{2}{*}{ Systems } & \multirow[t]{2}{*}{$\mathrm{OCP}[\mathrm{V}$ vs. $\mathrm{Ag}(\mathrm{s}) / \mathrm{AgCl}(\mathrm{s})]$} & \multirow[t]{2}{*}{ Different applied potentials [V vs. $\mathrm{Ag}_{(\mathrm{s})} / \mathrm{AgCl}_{(\mathrm{s})}$ ] } & \multicolumn{3}{|l|}{$f(\mathrm{~Hz})$} \\
\hline & & & $\mathrm{OCP}$ & $1.50 \mathrm{~V}$ & $2.00 \mathrm{~V}$ \\
\hline ITO/PCBM/P3MT & 0.760 & $1.50 ; 2.00$ & 12,589 & 79 & 5 \\
\hline ITO/PCBM/P3HT & 0.364 & $1.50 ; 2.00$ & 10,000 & 10,000 & 10 \\
\hline
\end{tabular}

Fig. 1 Cyclic voltammograms for ITO/P3AT and ITO/PCBM/ P3AT systems in $0.100 \mathrm{~mol} \mathrm{~L}^{-1} \mathrm{LiClO}_{4} / \mathrm{ACN}$ solution. a ITO/P3MT (solid line) and ITO/PCBM/P3MT (dashed line), b ITO/P3HT (solid line) and ITO/PCBM/ $\mathrm{P} 3 \mathrm{HT}$ (dashed line). $\mathrm{v}=50 \mathrm{mV} \mathrm{s}^{-1}$
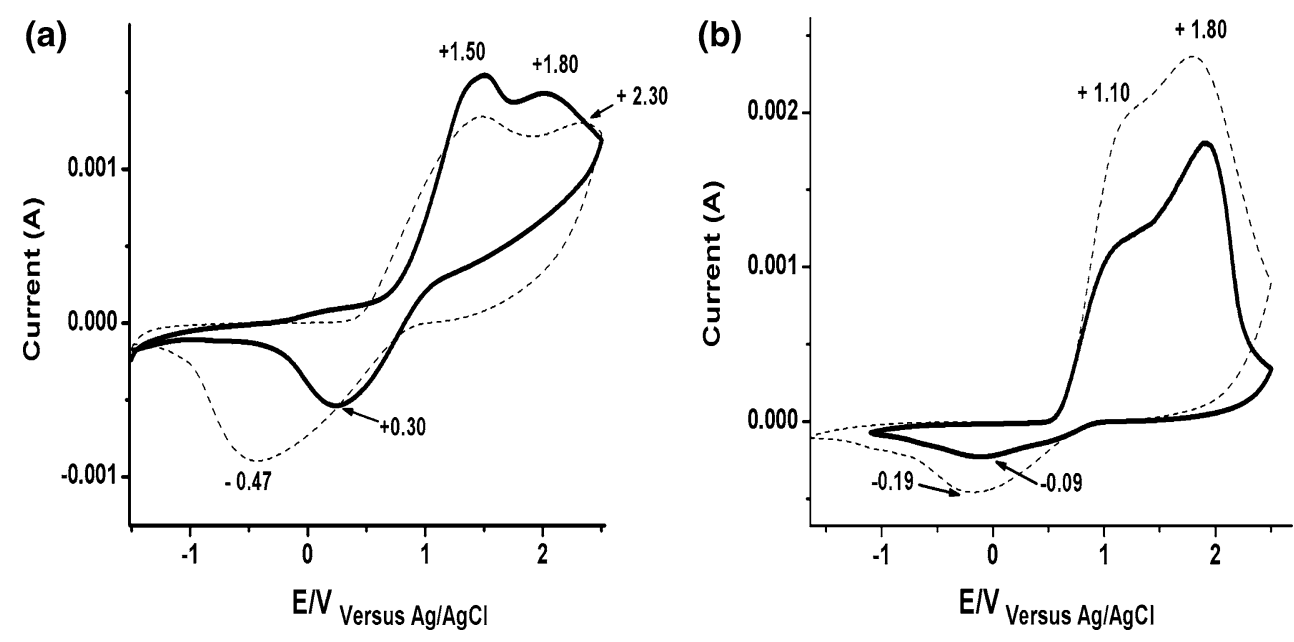

In Fig. 1b, oxidation peaks for ITO/P3HT and ITO/ $\mathrm{PCBM} / \mathrm{P} 3 \mathrm{HT}$ were close, around +1.10 and $+1.80 \mathrm{~V}$, and for ITO/PCBM/P3HT these peaks demonstrated an increase in current compared to the corresponding oxidation peaks for ITO/P3HT. This increase in current was also verified for reduction peaks for ITO/PCBM/P3HT, which also presented a negative displacement from -0.09 to $-0.19 \mathrm{~V}$

Comparing cyclic voltammetry for the ITO/P3ATs with that for the ITO/PCBM/P3ATs, it was verified that ITO/ PCBM/P3ATs demonstrate increased charge transfer as a result of an increase in peak current $[3,24]$. This increase in both anodic and cathodic current observed for ITO/ PCBM/P3HT suggests that charge transfer was higher than for ITO/PCBM/P3MT, for which only an increase in cathodic current was observed.

The displacement of the curves in $\mathrm{CV}$, and particularly of reduction peaks for the ITO/PCBM/P3AT systems, may have occurred as a result of modifications to charge transfer processes between PCBM and the P3ATs that must have led to the stabilization of species at a different stage of oxidation along the P3MT and P3HT polymer chains. This would have taken place as a result of alterations in the conformational arrangement of these polymer chains when interacting with PCBM [12].

Figure 2 presents Nyquist plots for ITO/PCBM/P3MT and ITO/PCBM/P3HT in a $0.100 \mathrm{~mol} \mathrm{~L}^{-1}$ solution of $\mathrm{LiClO}_{4} / \mathrm{ACN}$, obtained through the application of a range of potentials previously determined via $\mathrm{CV}$.

Nyquist plots for the two ITO/PCBM/P3AT systems demonstrated semicircles at high frequencies associated with charge transfer resistance processes at the ITO/ $\mathrm{PCBM} / \mathrm{P} 3 \mathrm{ATs} / \mathrm{ClO}_{4}{ }^{-}$interface, as observed in Nyquist plots for ITO/P3MT and ITO/P3HT obtained during a previous study [23].

Semicircles with increased diameters were observed on Nyquist plots for ITO/PCBM/P3ATs when higher potentials were applied, indicating a correlation between charge transfer resistance $\left(\mathrm{R}_{\mathrm{CT}}\right)$ and potential and demonstrating a transition in the conductive and resistive structure along the polymer chain [25]. Therefore, charge transfer resistance was higher when potentials close to the potential of the second peak were applied, which was obtained via cyclic voltammetry. This behaviour has also been observed for 
Fig. 2 Nyquist plots obtained at different potentials for a ITO/ PCBM/P3MT and b ITO/ $\mathrm{PCBM} / \mathrm{P} 3 \mathrm{HT}$ in $0.100 \mathrm{~mol} \mathrm{~L}^{-1}$ $\mathrm{LiClO}_{4} / \mathrm{ACN}$ solution

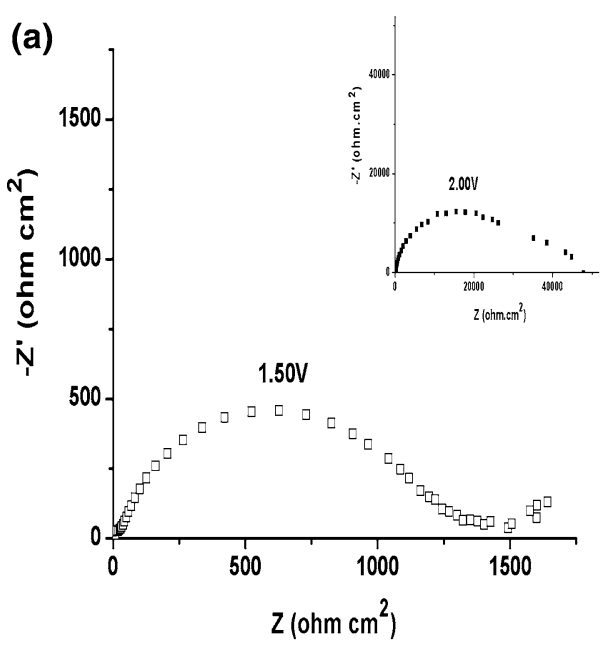

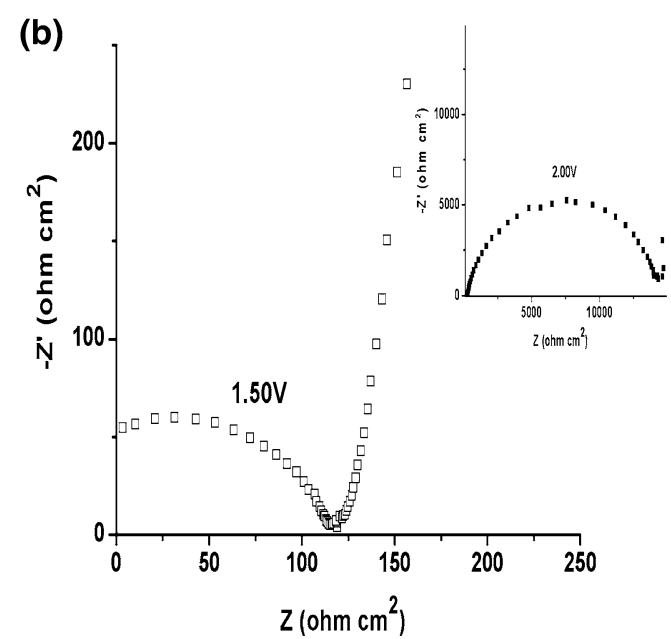

P3MT and P3HT films synthesized onto ITO, and the increase in charge transfer resistance was attributed to the stabilization of the dication species along the polymer matrix [23].

The semicircles on the Nyquist plots presented in Fig. 2 were also used to determine $\mathrm{R}_{\mathrm{CT}}$ values. For ITO/PCBM/ $\mathrm{P} 3 \mathrm{MT}$ and ITO/PCBM/P3HT with the application of $+1.50 \mathrm{~V}, \mathrm{R}_{\mathrm{CT}}$ values were $1.30 \times 10^{3}$ and $1.11 \times$ $10^{2} \Omega \mathrm{cm}^{2}$ respectively. With the application of $+2.00 \mathrm{~V}$, $\mathrm{R}_{\mathrm{CT}}$ values were $4.8 \times 10^{4}$ and $1.40 \times 10^{4} \Omega \mathrm{cm}^{2}$ respectively. These values prove that there is an increase in the resistivity of these materials at potentials similar to that of the second oxidation peak, and they also show that there was a more pronounced charge transfer process for ITO/ $\mathrm{PCBM} / \mathrm{P} 3 \mathrm{HT}$ than for ITO/PCBM/P3MT, as the former was less resistive. This data backs up the results observed for cyclic voltammetry of ITO/PCBM/P3HT, presented in Fig. 1b, for which an increase in anodic current was verified.

It was verified that $\mathrm{R}_{\mathrm{CT}}$ values for ITO/PCBM/P3HT for the first and second potential applied when compared to $\mathrm{R}_{\mathrm{CT}}$ values for ITO/P3HT [23] presented a reduction of $1.75 \times 10^{2} \Omega \mathrm{cm}^{2}$ when the potential of the first peak was applied and $6.17 \times 10^{5} \Omega \mathrm{cm}^{2}$ when the potential of the second peak was applied. For ITO/PCBM/P3MT, there was an increase in $\mathrm{R}_{\mathrm{CT}}$ of $4.77 \times 10^{2}$ and $4.62 \times 10^{4} \Omega \mathrm{cm}^{2}$ for the first and second peaks applied respectively compared to values for ITO/P3MT [23]. Therefore, the addition of PCBM could cause an alteration in the configuration of the P3HT polymer matrix, giving it more conductive properties [12].

Figure 3 presents ex situ Raman spectra for ITO/PCBM, ITO/PCBM/P3MT and ITO/PCBM/P3HT using exciting radiation at a wavelength of $532 \mathrm{~nm}$.

The bands observed at 1422 and $1461 \mathrm{~cm}^{-1}$ in the Raman spectra for ITO/PCBM, presented in Fig. 3a, are related to the $\mathrm{H} g(7)$ and $\mathrm{A} g(2)$ forms of $\mathrm{C}_{60}$ respectively.
The band at $1461 \mathrm{~cm}^{-1}$ is intense, as it is related to the more prominent form $\mathrm{C}_{60}[19,20]$. Spectra for ITO/PCBM/ P3MT, presented in Fig. 3c, and ITO/PCBM/P3HT, presented in Fig. 3b, were similar to those for P3ATs synthesized onto ITO [23], as the band at $1452 \mathrm{~cm}^{-1}$ for both compounds was attributed to $v_{\mathrm{s}}\left(\mathrm{C}=\mathrm{C}_{\text {ring }}\right)[23,26-30]$.

Considering the results observed using $\mathrm{CV}$ and EIS where possible interactions between the P3ATs and PCBM were verified for the different potentials applied, in situ Raman spectra of these materials were obtained with the objective of monitoring structural changes to the P3AT polymeric chain in the presence of PCBM during electrochemical oxidation and reduction processes.

To provide a better analysis, the spectral region between 1400 and $1580 \mathrm{~cm}^{-1}$ for the Raman spectra for ITO/

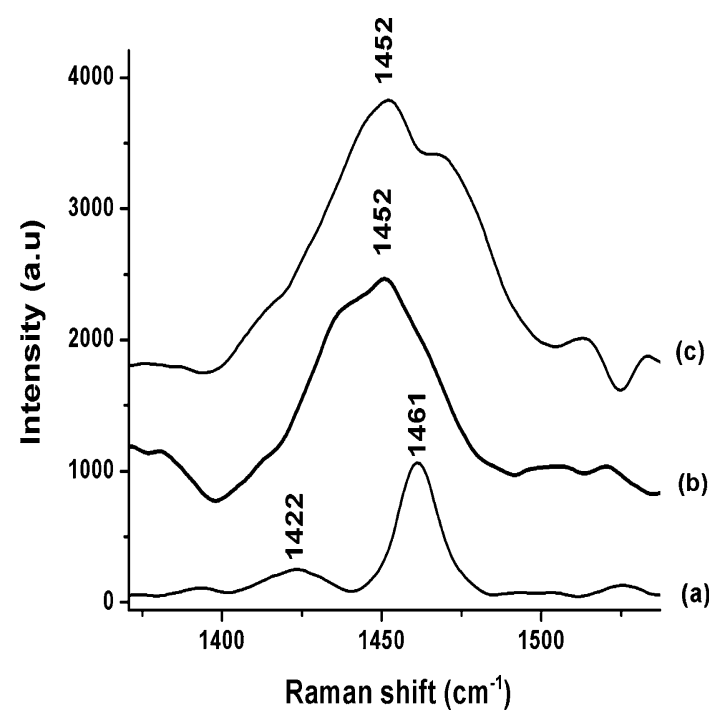

Fig. 3 Ex situ Raman spectra for $a$ ITO/PCBM, $b$ ITO/PCBM/P3HT and $c$ ITO/PCBM/P3MT, obtained using radiation at a wavelength of $532 \mathrm{~nm}$ 
PCBM/P3ATs and ITO/P3ATs were deconvoluted. This region is important, as in P3ATs it refers to the characteristic frequencies of $\mathrm{C}=\mathrm{C}$ symmetrical stretching in the thiophenic ring that are sensitive to modifications to the P3AT polymer chain [3, 23, 26-30].

Figure 4 presents deconvoluted in situ Raman spectra for ITO/P3HT and ITO/PCBM/P3HT obtained at potentials similar to the respective oxidation and reduction potentials for each system observed using $\mathrm{CV}$, shown previously in Fig. 1.

Figure 4 presents deconvoluted in situ Raman spectra for ITO/P3HT and ITO/PCBM/P3HT with bands around 1434-1438, 1444-1445 and 1453-1463 $\mathrm{cm}^{-1}$ associated with the P3HT aromatic species, radical dication and cation radical respectively, with differing intensities [23].

A displacement to lower wavelengths of the bands relating to these three species was observed for ITO/P3HT and ITO/PCBM/P3HT, presented in Fig. 4a, e, with the application of $0.00 \mathrm{~V}$, and the band at $1453-1457 \mathrm{~cm}^{-1}$ intensified, indicating a stabilization of the radical cation species in the polymer matrix under these conditions. With the application of $+1.20 \mathrm{~V}$, the deconvoluted spectrum for ITO/P3HT, presented in Fig. 4b, demonstrated a more intense band at $1445 \mathrm{~cm}^{-1}$, and in the spectrum for ITO/ PCBM/P3HT, presented in Fig. 4f, there was a more intense band at $1459 \mathrm{~cm}^{-1}$. Therefore, at this potential there was a stabilization of the cation species in ITO/P3HT and a stabilization of the radical cation species in ITO/ PCBM/P3HT. The spectra in Fig. 4c-g, with an application of $+1.80 \mathrm{~V}$, also demonstrated stabilization of the dication species in ITO/P3HT and the radical cation in ITO/PCBM/ $\mathrm{P} 3 \mathrm{HT}$. A wide band with low intensity appeared in the former at $1444 \mathrm{~cm}^{-1}$ relating to the dication, which was not observed in the spectrum for ITO/PCBM/P3HT with the application of $+1.20 \mathrm{~V}$.

Deconvoluted in situ Raman spectra for ITO/P3HT and ITO/PCBM/P3HT were also obtained for an application of $-0.20 \mathrm{~V}$, referring to the reduction of these systems. After being deconvoluted, the ITO/P3HT spectrum, presented in Fig. 4d, demonstrated bands associated with the aromatic and radical cation, the former being more intense than the latter. For ITO/PCBM/P3HT, presented in Fig. 4h, bands associated with the three species were observed, with the band relating to the radical cation having the highest intensity.

Therefore, based on deconvoluted in situ Raman spectra, presented in Fig. 4, it was determined that the production of ITO/PCBM/P3HT resulted in the P3HT polymer having a more stable radical cation species, and that this behaviour was not observed for deconvoluted ITO/P3HT spectra. For this reason, it can be affirmed that the increases in anodic and cathodic current observed in the cyclic voltammograms, presented in Fig. $1 \mathrm{~b}$, and the reduction of $\mathrm{R}_{\mathrm{CT}}$ determined using Nyquist plots, presented in Fig. $2 b$, for ITO/PCBM/P3HT in relation to ITO/P3HT, were a result of the increased stabilization of the radical cation species along the polymer, which could favour the charge transfer process in the interaction between PCBM and P3HT [10].

Figure 5 presents deconvoluted in situ Raman spectra for ITO/P3MT and ITO/PCBM/P3MT obtained for potentials similar to the oxidation and reduction potentials observed via cyclic voltammetry for each system, presented in Fig. 1.

In the deconvoluted in situ Raman spectra for ITO/P3MT and ITO/PCBM/P3MT, presented in Fig. 5, two bands were observed relating to the aromatic and dication species at $1420-1444$ and $1450-1463 \mathrm{~cm}^{-1}$ respectively [23].

In the spectra for ITO/P3MT, presented in Fig. 5a-d, in addition to the band related to the dication segment, the band related to the aromatic segment intensified as a result of the resonant Raman effect. For ITO/PCBM/P3MT, presented in Fig. 5e-h, application of potential also demonstrated a stabilization of the dication species in this material. These results indicate that variations do not occur along the P3MT polymer structure when this is generated on PCBM.

Therefore, the data observed in the in situ Raman spectra for ITO/PCBM/P3MT, presented in Fig. 5e-h, characterizes the higher $\mathrm{R}_{\mathrm{CT}}$ values determined for this system in relation to ITO/PCBM/P3HT observed on the Nyquist plot, presented in Fig. 2, as a result of the stabilization of the dication species in this material. As established in a previous study, the stabilization of the dication species gives the polymer a higher charge transfer resistance [23].

Given the results obtained through Raman spectroscopy, the variations observed in $R_{C T}$ could be related to the presence of different structures along P3AT polymer chains, which are responsible for polaron (radical cation) and bipolar (dication) conduction, which can be observed a low frequencies in Bode phase plots [23, 31].

Therefore, in order to supplement the study of different charge transfer processes in ITO/PCBM/P3AT systems, Bode phase plots were obtained from data generated through EIS at different potentials, presented in Fig. 6a, b, and at OCP, presented in Fig. 6c, d. Figure 6c, d present Bode phase plots for ITO/P3MT and ITO/P3HT obtained in a previous study [23].

The Bode phase plots for ITO/PCBM/P3ATs presented in Fig. 6 demonstrate phases at different time constants, relating to polaron, bipolaron and electronic conduction $[23,31]$. This behaviour has also been observed for P3ATs deposited with copolymers onto a platinum and ITO electrode $[23,28]$.

For ITO/PCBM/P3MT, presented in Fig. 6a, no variation in the phase relating to electronic conduction was 

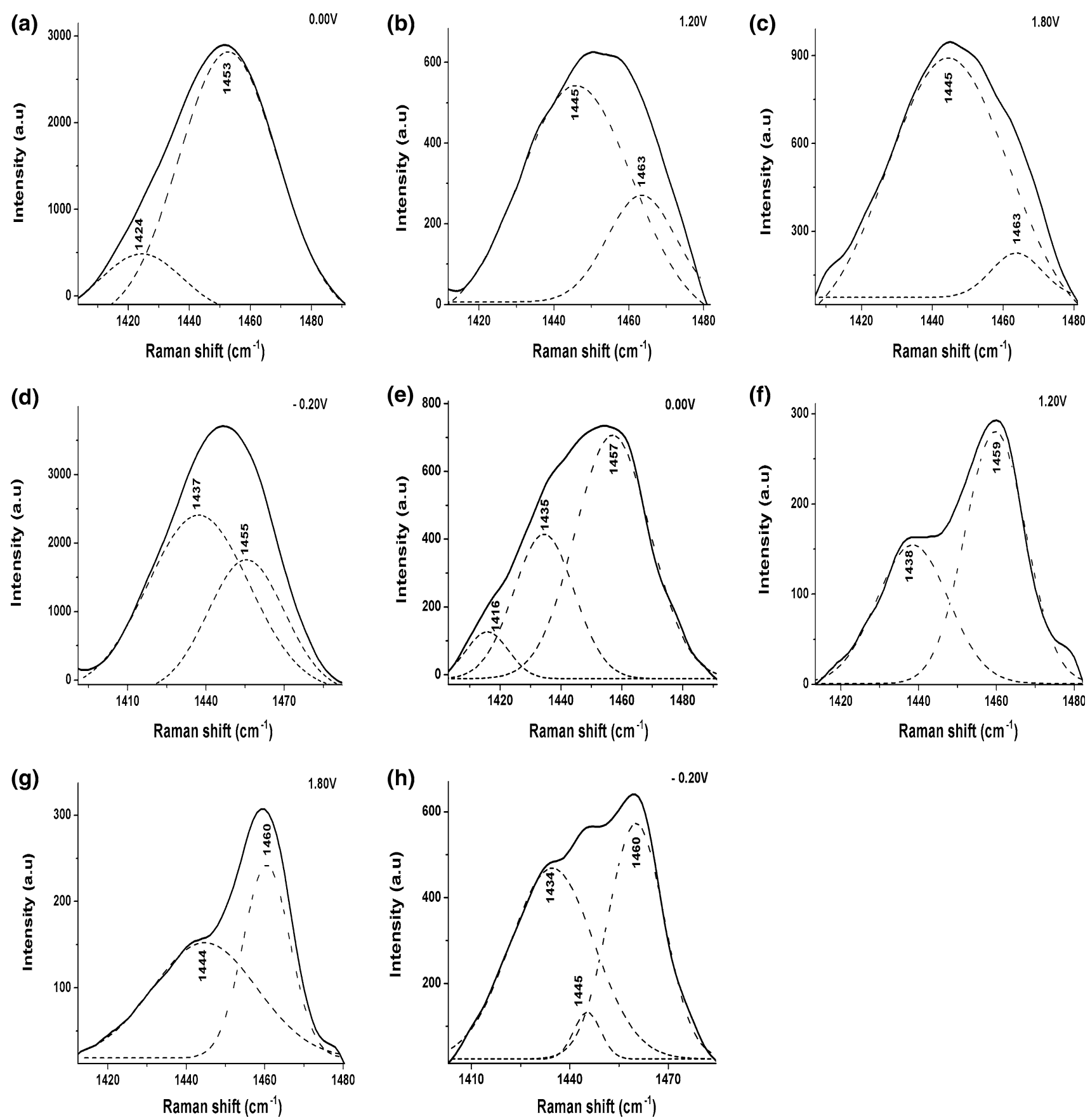

Fig. 4 Deconvoluted in situ Raman spectra for ITO/P3HT systems (a-d) and ITO/PCBM/P3HT systems $(\mathbf{e}-\mathbf{h})$ in $0.100 \mathrm{~mol} \mathrm{~L}^{-1} \mathrm{LiClO}_{4} /$ $\mathrm{ACN}$ solution obtained at potentials similar to those for the oxidation

and reduction potentials observed in their respective CV. Electrochemical potentials are indicated in each figure

verified for different potentials. At low frequencies, only the phase relating to bipolar conduction was observed, which with a potential of $+1.50 \mathrm{~V}$ was situated at $341 \mathrm{~Hz}$ at a phase angle of $54\left({ }^{\circ}\right)$, and with the application of $+2.00 \mathrm{~V}$ this was displaced to a frequency of $94 \mathrm{~Hz}$ and intensified at a phase angle of $79\left(^{\circ}\right)$. For ITO/PCBM/ $\mathrm{P} 3 \mathrm{HT}$, presented in Fig. $6 \mathrm{~b}$, there were no alterations to the phase relating to electronic conduction at different potentials. At low frequencies, with the application of $+1.50 \mathrm{~V}$, the phase relating to polaron conduction was observed at $0.05 \mathrm{~Hz}$ at a phase angle of $70\left(^{\circ}\right)$, and with the application of $+2.00 \mathrm{~V}$ this phase disappeared and the phase relating to bipolar conduction could be observed at $121 \mathrm{~Hz}$ at a phase angle of $66\left(^{\circ}\right)$. 

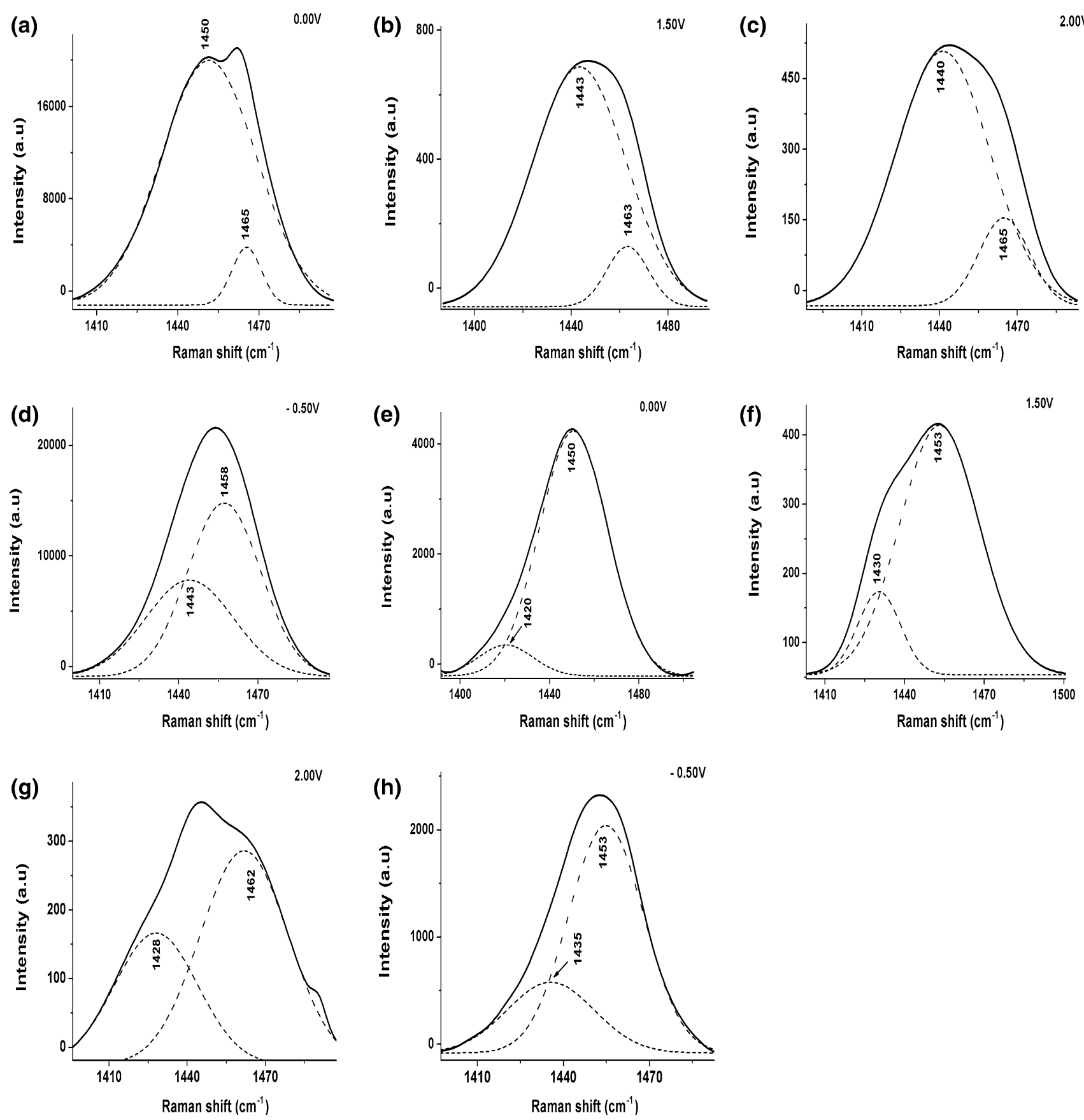

Fig. 5 Deconvoluted in situ Raman spectra for ITO/P3MT (a-d) and ITO/PCBM/P3MT (e-h) in $0.100 \mathrm{~mol} \mathrm{~L}^{-1} \mathrm{LiClO}_{4} / \mathrm{ACN}$ solution obtained at potentials similar to those for the oxidation and reduction

These results demonstrate that the lower value of $R_{C T}$ observed in Nyquist plots for ITO/PCBM/P3HT, presented in Fig. $2 b$, was a result of polaron conduction related to the stabilization of the radical cation species in the polymeric matrix of this material. The higher $\mathrm{R}_{\mathrm{CT}}$ values observed in Nyquist plots for ITO/PCBM/P3MT, presented in Fig. 2a, was influenced by the bipolar conduction resulting from the stabilization of the dication species in this material. potentials observed in their respective $\mathrm{CV}$. Electrochemical potentials are indicated in each figure

In Bode phase plots at OCP for ITO/PCBM/P3MT, compared to those for ITO/P3MT, presented in Fig. 6c, just the displaced phase relating to bipolar conduction was observed at low frequencies. In addition, the phase relating to electronic conduction was verified at a lower phase angle compared to that for ITO/P3MT at high frequencies [23]. This appearance of just the bipolar phase at low frequencies and the reduction of the phase angle relating to 
Fig. 6 Bode phase plots generated for the following systems in $0.100 \mathrm{~mol} \mathrm{~L}^{-1}$ $\mathrm{LiClO}_{4} / \mathrm{CAN}$ solution at different potentials a ITO/ PCBM/P3MT and b ITO/ $\mathrm{PCBM} / \mathrm{P} 3 \mathrm{HT}$ at OCP c ITO/ P3MT (open square) and ITO/ $\mathrm{PCBM} / \mathrm{P} 3 \mathrm{MT}$ (filled square), d ITO/P3HT (open square) and ITO/PCBM/P3HT (filled square)
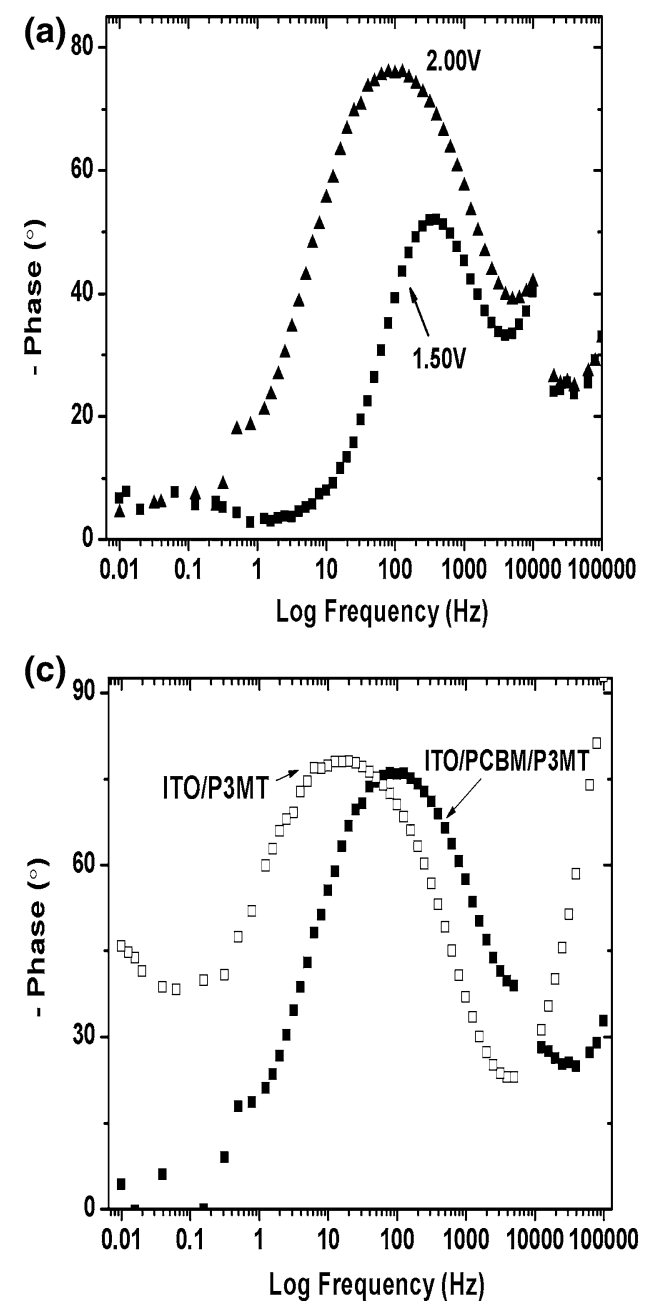

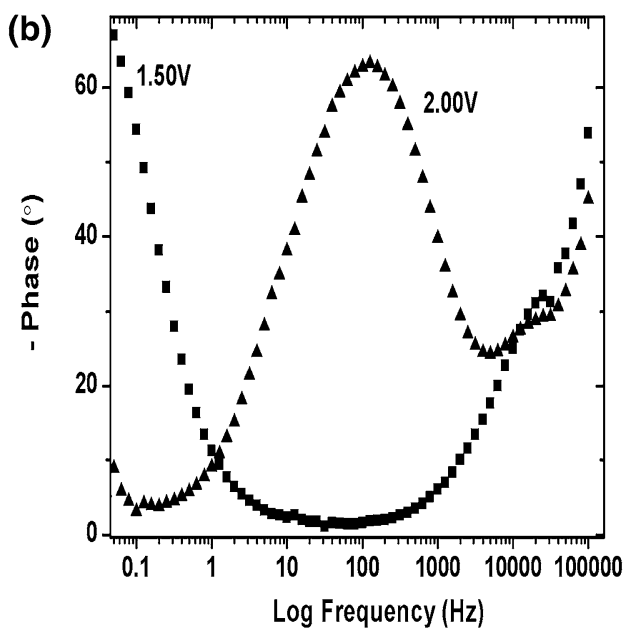

(d)

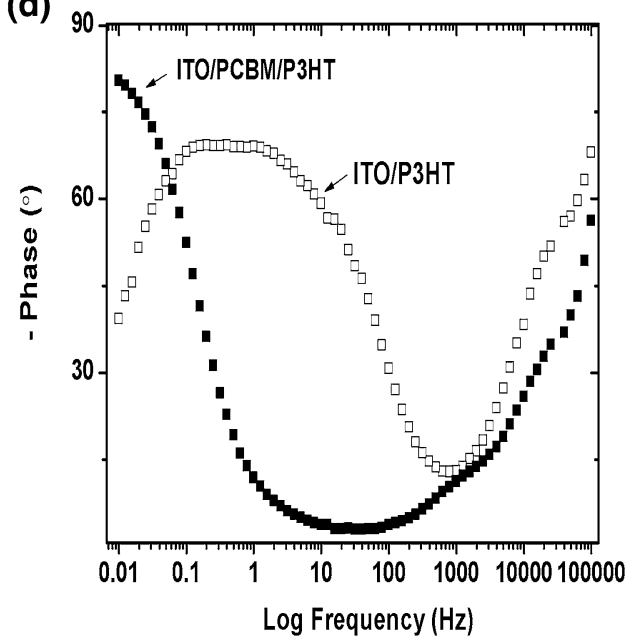

electronic conduction for ITO/PCBM/P3MT confirm the higher $\mathrm{R}_{\mathrm{CT}}$ values and show that these were a result of the dication species. For plots at OCP for ITO/PCBM/P3HT, presented in Fig. 6d, when compared to those for ITO/ P3HT [23], only the phase relating to polaron conduction was verified at higher phase angles, confirming that the increased charge transfer for this polymer is a result of the stabilization of the radical cation species.

\section{Conclusion}

The results observed for cyclic voltammetry, electrochemical impedance spectroscopy and Raman spectroscopy demonstrate that it is possible to obtain P3AT films with modified electrochemical behaviour as a result of charge transfer processes when these are integrated with PCBM.

Nyquist plots, obtained by performing EIS at different potentials, demonstrated the more resistive behaviour of these films at potentials similar to those for the second oxidation peak. $\mathrm{R}_{\mathrm{CT}}$ values obtained for ITO/PCBM/P3MT were higher than for ITO/P3MT, proving that in the former there was no improvement in charge transfer. The $\mathrm{R}_{\mathrm{TC}}$ value for ITO/PCBM/P3HT was lower compared to that for the other films, meaning that in this system there were more efficient charge transfer processes. Also obtained from EIS, Bode phase plots indicated that the lower charge transfer resistance for ITO/PCBM/P3HT is related to polaron conduction (radical cation), and for ITO/PCBM/ P3MT the higher charge transfer resistance is related to bipolar conduction (dication).

These electrochemical studies were supplemented using deconvoluted in situ Raman spectra, which demonstrated that the charge transfer process is a result of the stabilization of the radical cation species and the dication in the P3AT matrix. Therefore, the lower charge transfer resistance of ITO/PCBM/P3HT was a result of the stabilization of the radical cation in the P3HT matrix, and the higher charge transfer resistance for ITO/PCBM/P3MT was a result of the stabilization of the dication in the P3MT matrix. Therefore, in the polymeric chain of the $\mathrm{P} 3 \mathrm{HT}$ film 
synthesized onto PCBM, there was an increased generation of the radical cation species (positive polaron), which promoted a higher charge transfer in the ITO/PCBM/P3HT system, meaning that this system would be better as the active layer in OPVs and would make energy conversion more efficient in these cells.

Acknowledgments We would like to express our appreciation to the Spectroscopy Laboratory (SPEC) at the PROPPG/UEL Multiuser Center and the National Council for Scientific and Technological Development $(\mathrm{CNPq})$ for their financial support (Project No. 441689/2014-0). D.C. Bento is indebted to the Coordination for the Improvement of Higher Education Personnel (CAPES) for the grant of a fellowship.

\section{References}

1. M.-C. Chen, S. Kar, D.-J. Liaw, W.-H. Chen, Y.-C. Huang, Y. Tai, Org. Electron. 13, 2702 (2012)

2. C.W. Lin, D.Y. Wang, Y.T. Wang, C.C. Chen, Y.J. Yang, Y.F. Chen, Sol. Energy Mater. Sol. Cells 95, 107 (2011)

3. D. Momodu, A. Bello, J. Dangbegnon, F. Barzeger, M. Fabiane, N. Manyala, J. Solid State Electrochem. 19, 445 (2015)

4. J. Yang, D. Vak, N. Clark, J. Subbiah, W.W.H. WonG, D.J. Jones, S.E. Watkins, G. Wilson, Sol. Energy Mater. Sol. Cells 109, 47 (2013)

5. L.-M. Chen, Z. Hong, G. Li, Y. Yang, Adv. Mater. (Weinheim, Ger.) 21, 1434 (2009)

6. P. Morvillo, I.A. Grimaldi, R. Diana, F. Loffredo, F. Villani, J. Mater. Sci. 48, 2920 (2013)

7. P. Veerender, V. Saxena, A.K. Chauhan, S.P. Koiry, P. Jha, A. Gusain, S. Choudhury, D.K. Aswal, S.K. Gupta, J. Sol. Energy Mater. Sol. Cells. 120, 526 (2014)

8. C.L. Chochos, S.A. Choulis, Prog. Polym. Sci. 36, 1326 (2011)

9. A.A. Zakhidov, T. Akashia, K. Yoshino, Synth. Met. 70, 1519 (1995)

10. K. Marumoto, N. Takeuchi, T. Ozak, S. Kuroda, Synth. Met. 129, 239 (2002)

11. P. Vanlaeke, A. Swinnen, I. Haeldermans, G. Vanhoyland, T. Aernouts, D. Cheyns, C. Deibel, J. D'haen, P. Heremans, J.S. Poortman, J.V. Manca, J. Sol. Energy Mater. Sol. Cells. 90, 2150 (2006)
12. Y.-J. Cheng, S.-H. Yang, C.-S. Hsu, Chem. Rev. 109, 5868 (2009)

13. J. Mikroyannidi, A.N. Kabanakis, S.S. Sharma, G.D. Sharma, Adv. Funct. Mater. 21, 746 (2011)

14. S. Wilken, D. Scheunemann, V. Wilkens, J. Parisi, H. Borchert, Org. Electron. 13, 2386 (2012)

15. A. Bou, P. Torchio, S. Vedraine, D. Barakel, B. Lucas, J.-C. Bernède, P.-Y. Thoulon, M. Ricci, Sol. Energy Mater. Sol. Cells 125, 310 (2014)

16. J.D. Stenger-Smith, Prog. Polym. Sci. 23, 57 (1998)

17. L.H.C. Mattoso, Quím. Nova. 19, 388 (1996)

18. A. Ray, A.F. Richter, A.G. Macdiarmid, A.J. Epstein, Synth. Met. 29, E151 (1989)

19. H. Kuzmany, R. Pfeiffer, M. Hulman, C. Kramberger, Philos. Trans. R. Soc. Lond. A. 362, 2375 (2004)

20. S. Falke, P. Eravuchira, A. Materny, C. Lienaua, J. Raman Spectrosc. 42, 1897 (2011)

21. S. Nakazawa, K. Sato, D. Shiomi, M.L.T.M.B. Franco, M.C.R.L.R. Lazana, M.C.B.L. Shohoji, K. Itoh, T. Takui, Inorg. Chim. Acta 361, 4031 (2008)

22. O.J. Alley, M.-Y. Wu, G.L. Johns, T.J. Dawidczyk, J.F.M. Hardigree, N. Markovic, M.S. Arnold, H.E. Katz, Appl. Phys. Lett. 106, 033301 (2015)

23. D.C. Bento, E.C.R. Maia, T.N.M. Cervantes, C.A. Olivat, G. Louarn, H. De Santana, J. Mater. Sci. Mater. Electron. 26, 149 (2015)

24. N. Torabi, A. Behjat, F. Jafari, Thin Solid Films 573, 112 (2014)

25. L.F. Marchesi, E.C. Pereira, Synth. Met. 194, 82 (2014)

26. H. De Santana, E.C.R. Maia, D.C. Bento, T.N.M. Cervantes, G.J. Moore, J. Mater. Sci. Mater. Electron. 24, 3352 (2013)

27. E.C.R. Maia, D.C. Bento, E. Laureto, D.A.M. Zaia, E.M. Therézio, G.J. Moore, H. De Santana, J. Serb. Chem. Soc. 78, 507 (2013)

28. T.N.M. Cervantes, D.C. Bento, E.C.R. Maia, R.V. Fernandes, E. Laureto, G.J. Moore, G. Louarn, H. De Santana, J. Mater. Sci. Mater. Electron. 25, 1703 (2014)

29. D.C. Bento, E.C.R. Maia, T.N.M. Cervantes, R.V. Fernandes, E. Di Mauro, E. Laureto, M.A.T. Da Silva, J.L. Duarte, I.F.L. Dias, H. de Santana, Synth. Met. 162, 2433 (2012)

30. G. Louarn, J.-Y. Mevellec, J.P. Buisson, S. Lefrant, Synt. Met. 55, 587 (1993)

31. G. Lillie, P. Payne, P. Vadgama, Sens. Actuators B 78, 249 (2001) 